\title{
Mulemba
}

Revista Angolana de Ciências Sociais

6 (12) | 2016

Sobre a sociedade e a cultura em Angola e alhures:

algumas reflexões de percepções sobre a realidade e múltiplas experiências

\section{A percepção da educação desde a perspectiva sociológica}

The perception of education from a sociological perspective

\section{António Inácio Rocha Santana}

\section{OpenEdition \\ Journals}

\section{Edição electrónica}

URL: http://journals.openedition.org/mulemba/853

DOI: 10.4000/mulemba.853

ISSN: 2520-0305

\section{Editora}

Edições Pedago

Edição impressa

Data de publição: 1 novembro 2016

Paginação: 91-120

ISSN: 2182-6471

Refêrencia eletrónica

António Inácio Rocha Santana, «A percepção da educação desde a perspectiva sociológica», Mulemba [Online], 6 (12) | 2016, posto online no dia 30 setembro 2018, consultado o 26 janeiro 2021. URL:

http://journals.openedition.org/mulemba/853 ; DOI: https://doi.org/10.4000/mulemba.853 


\title{
A percepção da educação desde a perspectiva sociológica
}

\author{
António Inácio Rocha Santana*
}

\begin{abstract}
Resumo: Este texto pretende debater o conhecimento dos principais teóricos clássicos e neoclássicos da sociologia da educação mediante a resenha das ideias de K. Marx e E. Durkheim, K. Mannheim e T. Parsons. Percebe-se, nesta trilogia reflexiva, uma grande convergência de ideias que podem se considerar complementares na prática educativa visto que exprimem, de maneira geral, a análise das instituições e organizações da educação, mas que este exame só cobra sentido quando ligado às relações funcionais entre a educação e as outras ordens institucionais da sociedade, tais como a economia, a religião, a política e a família. Por essa razão, à escola da sociedade da informação e comunicação é exigido revisitar suas relações com as outras modalidades de educação não formal para articular-se e integrar-se a elas e liderar o processo de socialização do conhecimento, visando a formação de cidadãos melhor preparados e qualificados para corresponder às novas demandas sociais.
\end{abstract}

Palavras-Chave: Sociologia da educação, K. Marx, E. Durkheim, E. Mannheim, T. Parsons.

\section{Introdução}

O presente ensaio visa reflectir sobre a sociologia da educação na visão de seus principais teóricos clássicos e neoclássicos através de uma síntese de suas ideias. Basicamente, os pontos principais de apoio de nossa discussão assentam em Marx e Durkheim (os grandes clássicos), e Mannheim e Parsons (em representação dos neoclássicos). Os primeiros detêm praticamente o núcleo teórico e metodológico da disciplina e constituirão, logicamente, o fio teórico condutor

* Sociólogo. Director-Geral da Escola Superior Pedagógica do Kwanza Norte e docente do Departamento de Sociologia da Faculdade de Ciências Sociais (FCS) da Universidade Agostinho Neto (UAN). 
para discutir, no possível, alguns factos conhecidos dentro de determinado horizonte empírico e heurístico.

Concretamente, pretendemos debater o conhecimento desses autores e tendências a partir da análise temática, sistemática e sintética de uma boa parte de seus textos fundamentais e no marco histórico e teórico correspondente a cada um deles. Deste modo, partimos da distinção de três níveis problemáticos básicos, objectiva e epistemologicamente hierarquizados: o nível macrossociológico e holístico da sociologia da educação (Marx e Durkheim); um nível intermédio, correspondente à sociologia do sistema de ensino (Mannheim); e o nível microssociológico próprio da sociologia da sala escolar (Parsons).

A discussão apresentada discorre sobre a questão de saber como se percebe a educação, enquanto fenómeno social, desde a perspectiva clássica e neoclássica da sociologia. A educação, como qualquer outro fenómeno social, não pode ser bem explicada a não ser no horizonte integrador e unitário do meio biológico específico do ser humano (a cultura). O que entendemos por educação compreende um campo de fenómenos mais vasto do que o correspondente ao sistema de ensino característico da sociedade moderna; naturalmente, esse sistema escolar não pode, de maneira nenhuma, entender-se fora do contexto da educação e da cultura dessa sociedade (MIr 1990).

Todos os clássicos e neoclássicos da sociologia da educação colocam o problema da escola no quadro geral da sociologia da educação e da cultura. Assim, enquanto em Marx a sociologia do sistema de ensino aparece como algo relativamente periférico, a sociologia da educação é algo nuclear em Durkheim. Além disso, a sua sociologia do sistema de ensino inclui aspectos tão fundamentais como uma sociologia histórica rigorosa e muito original, uma sociologia da reforma do ensino secundário e uma sociologia do currículo plenamente actual. Mannheim aborda também, mais ou menos sistematicamente, a problemática geral da sociologia do sistema de ensino. Mas, a sociologia da sala de aula só aparece com Parsons, que parte da análise funcionalista da escola como subsistema social. O potenciamento definitivo dessa sociologia da sala de aula só aconteceu com o amadurecimento da «nova sociologia da educação», que emergiu com a crise geral da sociologia «ocidental», quase no limite da década de setenta, a partir de duas orientações fundamentais: microssociológica, subjectivista e interaccionista (de matriz epistemológica fenomenológica); e outra que defende a combinação da análise microssociológica e intersubjectiva com a macrossociológica e estrutural. 
O texto está estruturado em conformidade com a modalidade de abordagem proposta inicialmente, quer dizer: no primeiro momento, discute-se a sociologia da educação de Marx; no segundo, a sociologia da educação de Durkheim; no terceiro, a sociologia da educação de Mannheim; no quarto, a sociologia da educação de Parsons; finalizando, traz-se uma síntese do que foi discutido, bem como algumas perspectivas.

\section{A sociologia da educação de K. Marx}

Apesar de Marx não ter estudado de forma sistemática a sociologia da educação, essa sociologia depreende-se de sua vasta obra e materiais críticos relacionados com sua sociologia do conhecimento (genealogia da consciência; teoria das ideologias; burocratização do saber e do Estado na sociedade moderna), com sua sociologia geral (relação entre educação e trabalho), e com a necessidade de definir politicamente a estratégia e a táctica educativas da classe trabalhadora (crítica da pedagogia burguesa e do sistema de ensino liberal). Sua fecundidade heurística foi mais do que provada pela vigência actual dos diferentes modelos de análise das correntes neomarxistas. Para efeito deste trabalho, apenas serão considerados ao debate a relação entre educação e trabalho, a crítica do elitismo político e pedagógico e a crítica da pedagogia burguesa e do sistema de ensino liberal.

\section{Educação e trabalho: lógica socio-histórica do trabalho}

A cultura tem duas dimensões básicas: a material e a simbólica linguística. A educação é um processo que consiste na inculcação social e interiorização do meio humano por cada indivíduo durante o processo de socialização. Dado que o homem está estritamente vinculado ao meio cultural - ele circula entre símbolos, na linguagem, e num universo transformado pelo poder de abstracção da linguagem e do pensamento humano - , a educação sempre implica um certo grau de coerção: os indivíduos têm de aprender a reconhecer a cultura material e a enriquecer a cultura em geral sobre a base da comunicação entre adultos e jovens e como resultado da aplicação de todo um conjunto de mecanismos sociais de inculcação simbólica e ideológica. 
A partir dessa realidade, a criatividade cultural de cada indivíduo pode enriquecer em maior ou em menor medida a sua própria cultura social, mas sempre dentro dos limites estruturais que a distinguem. Como refere Marx, a forma de acção e experiência que diferencia a espécie humana é o trabalho. Enquanto animal, o homem tem de produzir sua vida e fá-lo com o trabalho: a transformação da natureza que resulta da capacidade de raciocinar.

«Nós vemos o trabalho de uma forma em que pertence exclusivamente ao homem. Uma aranha executa operações semelhantes às do tecelão, e a abelha envergonha, pela construção das células do favo de mel, mais de um mestre pedreiro. Mas o que distingue vantajosamente o pior mestre pedreiro da melhor abelha é que o primeiro moldou a célula na sua cabeça antes de construí-la em cera. Ao concluir o processo de trabalho surge um resultado que antes do início do trabalho já existia na imaginação do trabalhador, ou idealmente. O trabalhador não só efectua uma mudança de forma do natural; no natural, enquanto efectiva sua própria meta, um objectivo que ele sabe que determina, como lei, o modo e a forma de suas acções e que ele tem de subordinar sua vontade. E essa subordinação não é um acto isolado. Além do esforço dos órgãos que trabalham, exige-se do trabalhador, durante todo o curso do trabalho, a vontade orientada para a meta, que se manifesta com atenção» (Marx 1975-1981, apud Mir 1990: 38).

Enquanto conjunto da actividade social, o trabalho transformase historicamente. E a sua função educativa é influenciada pelos factores socioeconómicos específicos da cultura em que o homem vive, assim como também depende em grande medida da direcção que em cada momento resulta das contradições entre os distintos interesses e grupos sociais. Porquanto núcleo da cultura, a organização social do trabalho constitui também o núcleo da educação do homem em cada sociedade particular. Assim, dado o facto de existir uma história social do trabalho, é permissível falar-se também de uma história geral da educação resultante do trabalho e da preparação social para o trabalho. Por exemplo:

«Nas condições de estreita solidariedade características da sociedade primitiva, o indivíduo se prepara para sua integração na produção mediante as brincadeiras, a vida quotidiana familiar, o trabalho junto aos adultos e certos ritos iniciáticos. No período da manufactura 
e do capitalismo fabril primitivo, começa-se com o uso da coacção e a violência materiais directas (recrutamento forçado dos trabalhadores mediante as leis de pobres, legislação contra a ociosidade e outros procedimentos similares) e se impõe uma divisão social do trabalho que, progressivamente, leva ao extremo a fragmentação do trabalho manual e criativo do artesão tradicional, por meio da especialização dos trabalhadores. Há um período, mais ou menos longo, em que as novas condições laborais ainda são incapazes de ter o completo domínio das antigas. Mas, quando este processo conclui, a necessidade objectiva de vender a própria força de trabalho para poder subsistir, a experiência familiar do trabalho, a multiplicação crescente das necessidades e outros factores sociais determinam a aprendizagem mais ou menos espontânea da cultura económica burguesa. Trata-se de uma cultura que aumenta extraordinariamente a produtividade e o progresso técnico, ainda que à custa do desaparecimento das destrezas laborais mais seculares, da polarização entre a minoria dos especialistas e uma massa crescentemente desqualificada, da alienação geral» (MIR 1990: 48).

O próprio homem, enquanto espécie animal, é resultado do trabalho. Até à data presente, a história do trabalho tem sido sobretudo a história da alienação e da falsa consciência humanas. Trata-se de um processo dialéctico; não de um processo mecanicamente determinado. Com o amadurecimento do capitalismo aparece o perigo real não apenas da destruição da natureza, mas também da extinção da própria espécie. Mas ainda não há certezas definitivas. Marx não aposta no «fim da história», mas no «fim da pré-história». Quer dizer, pela construção de uma única cultura mundial de tipo progressivo a partir de uma organização do trabalho realmente solidária, consciente, universal (capaz de tornar toda a natureza seu objecto), livre (perante a necessidade física e perante os produtos do trabalho), total (capaz de estimular o desdobramento de todas as capacidades criativas do ser humano). Esta deve ser, na opinião de Mir (1990), a utopia para a qual direccionar a caminhada sobre uma base de análise científica do presente e de uma prática política radicalmente democrática. A história propriamente dita só começa com a superação dialéctica da alienação.

\section{Crítica do elitismo pedagógico}

Por meio das «onze teses sobre Feuerbach», Marx espelha de forma breve a sua concepção do mundo e do homem, através de notas 
publicadas por Engels em 1888. Dentre elas, a terceira tese proporciona uma lição crítica sobre as ligeirezas explicativas e ideológicas do elitismo cultural, em geral, e do elitismo pedagógico, em particular. Vejamos:

«A teoria materialista da mudança das circunstâncias e da educação esquece que as circunstâncias fazem mudar os homens e que o educador necessita de, por sua vez, ser educado. Tem, pois, de distinguir duas partes na sociedade, uma das quais se encontra colocada acima delas; por exemplo, Robert Owen.

A coincidência da mudança das circunstâncias com a da actividade humana ou a mudança dos próprios homens só pode conceber-se ou entender-se como prática revolucionária» (MARX \& ENGELS 1970: 666).

Desde o século xviII, o movimento reformista pedagógico tem seguido uma destas duas linhas básicas: a socrático-platónica ou rousseauniana e a política e ilustrada. A primeira enfatiza a libertação da consciência e de todas as virtualidades naturais de cada indivíduo humano, a remoção de toda a espécie de obstáculos culturais que possam dificultar ou prejudicar o seu desenvolvimento. A segunda direcção acentua a produção social da personalidade humana, a sua educação. O que interessa realmente não são as condições naturais do indivíduo, mas as «circunstâncias» sociais nas quais ele vive, porquanto sejam condições culturais que moldam sua mente. Na visão de Marx, cada uma dessas posições retrata tão-somente a metade da verdade: nem o indivíduo nasce feito, nem é apenas um puro resultado social.

A relação entre cada homem e o seu meio social é sempre uma relação dialéctica, mútua: não há indivíduos humanos sem sociedade, nem sociedades humanas sem indivíduos humanos. O homem é um produto social, cultural. Mas, são os homens - os homens individuais e concretos - que constroem a sociedade, criam a cultura e fazem a história; isso ocorre em condições sociais, culturais e históricas determinadas, e na medida em que prévia e paralelamente as vão dominando.

O materialismo ilustrado teoriza sobre este tópico, quando matiza o seu determinismo social no sentido elitista: há uma minoria de homens criativos, nascidos para «educar o povo mas sem o povo", e uma massa enorme de gente passiva, incapaz de actuar sem a ajuda da «classe directiva» da sociedade. A terceira tese 
sobre Feuerbach é dirigida directamente contra os ilustrados que confiavam na omnipotência da educação como arma para a reforma política, e contra aqueles socialistas utópicos que (como Owen) concebiam a relação entre indivíduo e o meio humano de forma igualmente mecanicista.

Marx enaltece não só a rotura dos ilustrados franceses com o idealismo filosófico, mas também o experimento educativo de New Lanark de Owen, por ter acertado em combinar a instrução escolar com a participação das crianças no trabalho dos adultos. Mas denuncia com veemência as verdades a meias do elitismo reformista cultural e pedagógico em geral. São os homens - todos os homens - que mudam as circunstâncias, e «o educador necessita por sua vez ser educado», pela simples razão de que «os homens fazem-se sempre todos uns aos outros»: na medida em que criam a cultura e mudam a sociedade, mudam também a educação e se transformam, também, a si mesmos.

Ora, essa mudança não pode processar-se mais além da evolução social e da reforma política e ideológica. A «coincidência da mudança das circunstâncias com a da actividade humana ou mudança dos próprios homens», quer dizer, a coincidência da mudança radical da cultura, da educação e do homem só é possível quando tem lugar uma revolução histórica (como, por exemplo, a substituição definitiva do feudalismo pelo capitalismo como modo de produção dominante).

\section{Crítica da pedagogia e do sistema de ensino liberal}

Em sua obra, Marx não parte nunca do homem e da sociedade abstracta, mas do homem e da sociedade concreta do seu tempo. Para Marx, a forma de existência histórica real de cada homem e de cada classe ou grupo social é o factor mais determinante de sua educação e de sua visão do mundo. Naturalmente, o que mais lhe interessa é a análise crítica da escola e da pedagogia de sua época, a escola e a pedagogia liberal.

Diante da realidade crua, vivente e evidente, reflectida no divórcio entre o ensino escolar e o trabalho produtivo (típico do sistema educativo burguês), Marx ressalta a importância nuclear da educação no trabalho e defende a articulação da instrução escolar e da educação laboral, do trabalho intelectual e do trabalho manual. Mas isso não deveria ser feito de forma desregrada, aliás, Marx é um crítico 
implacável, por exemplo, da exploração das crianças nas minas e nas fábricas de sua época (MonToYA 1986). Vejamos em concreto as suas palavras:

«Nós consideramos a tendência da indústria moderna em fazer cooperar as crianças e os adolescentes de ambos os sexos na grande obra da produção social como um progresso legítimo e saudável, embora a forma com que esta tendência se realiza sob o reino do capital seja simplesmente abominável» (MARX \& ENGELS 1978: 101).

«Embora tomadas em conjunto, as cláusulas educacionais da lei fabril são pobres, proclamam o ensino elementar como condição obrigatória do trabalho. Seu êxito demonstra, em primeiro lugar, a possibilidade de combinar a instrução e a ginástica com o trabalho manual, e, portanto, também a de combinar o trabalho manual com a instrução e a ginástica. Os inspectores fabris cedo descobriram, pelas declarações testemunhais dos professores de escola, que os miúdos das fábricas, embora só desfrutassem da metade do ensino, aprendiam tanto quanto os alunos correntes que assistiam às aulas durante o dia todo, e com frequência mais que estes. [...] Do sistema fabril, como podemos ver em detalhe na obra de R. Owen, brota o gérmen da educação do futuro, que combinará para todas as crianças, a partir de certa idade, o trabalho produtivo com a educação e a ginástica, não só como método de acrescentar a produção social, mas como único método para a produção de homens desenvolvidos de maneira omnifacética» (Marx 1975-1981, apud Mir 1990: 61).

Além disso, existem outros textos que permitem matizar mais esta posição de Marx. Em 1875 insistia na necessidade de determinar o limite de idade correspondente à exigência socialista da proibição do trabalho infantil, vista a impossibilidade de suprimi-lo completamente no momento, e na conveniência de exigir a sua regulamentação política desde o ponto de vista dos interesses e da cultura particulares da classe trabalhadora. Segundo o autor,

«A proibição do trabalho infantil é incompatível com a existência da grande indústria, e, portanto, um piedoso desejo, mas mais nada. Implementar esta proibição - supondo que fosse factível - seria reaccionário, já que, regulamentada severamente a jornada de trabalho de acordo com as distintas idades e aplicando as demais medidas 
preventivas para a protecção das crianças, a combinação do trabalho produtivo com o ensino desde a tenra idade é um dos mais potenciais meios de transformação da sociedade actual» (MARX 1968: 42-43).

Marx é um persistente defensor da combinação do trabalho com o ensino, porque muito cedo percebe a força educativa contida no trabalho conjunto de crianças e adultos. Acreditava que uma eventual separação deixaria os primeiros inermes perante o controle burguês do sistema escolar e perante os mecanismos ideológicos das classes dominantes em geral. Enquanto estas forças tratavam de identificar a educação genuína com o ensino escolar e impunham um sistema educativo essencialmente dual, que se distinguia por uma rígida separação entre o trabalho intelectual e o trabalho manual, a classe trabalhadora deveria, segundo ele, colocar toda a ênfase possível na estreita relação existente entre a participação no trabalho produtivo e a educação do indivíduo.

Para o alcance deste objectivo, a classe trabalhadora deveria lutar politicamente pela gratuitidade e neutralidade ideológica da escola. Marx queria para os alunos da classe trabalhadora o mínimo de educação escolar e o máximo de educação social no domínio da existência real. Consequente com este ideal, apoiou os programas políticos que propugnavam a separação da Igreja e do Estado e a substituição do padre ou sacerdote pelo professor, mas procurou também o controle popular da dimensão ideológica da escola na medida do possível, por exemplo, mediante a eliminação das disciplinas ideológicas e a definição estritamente técnica do currículo e dos programas de estudo. Em concreto, propõe o seguinte:

«Nas escolas elementares, e mais ainda nas escolas superiores, não se devem autorizar disciplinas que admitam uma interpretação de partido ou de classe. Na escola só se deve ensinar matérias tais como a gramática ou as ciências naturais. As regras gramaticais não mudam, quer seja um conservador clerical ou um livre-pensador que as ensina. Não se deve ensinar nas escolas aquelas matérias que admitem uma diversidade de conclusões» (MARX \& ENGELS 1978: 159).

Deste modo, Marx assentava as bases dos princípios da política educativa para a classe trabalhadora:

1. Combinação da instrução escolar e do trabalho produtivo; 
2. Controle popular da burocracia escolar e crítica da pedagogia burguesa;

3. Escola laica, obrigatória, gratuita e ideologicamente neutra;

4. Currículo técnico e integral: ensino intelectual, educação física e formação profissional.

O estabelecimento destes princípios teve a resistência esperada das forças sociais conservadoras opostas a este tipo de escolas, que Marx denunciou com firmeza e veemência em nome dos direitos naturais e sacrossantos da família e da liberdade da educação familiar, enquanto o capital destruía a família trabalhadora real e inclusive aproveitava-se do egoísmo dos pais moralmente mais degradados para intensificar a exploração de seus filhos. Desconfiava também da pequena burguesia, do magistério e da intelectualidade mesocrática que inspira as principais orientações reformistas da pedagogia e da política educativa do Estado liberal da época: a concepção meritocrática da escola (de Saint-Simon, por exemplo), o ludismo pedagógico (de Rousseau ou Fourier, entre outros), o naturalismo pedagógico rousseauniano e o dirigismo elitista e ilustrado. A crítica do ludismo pedagógico, concretamente, é bastante contundente: a educação não pode nunca ser um simples jogo; aprender na curiosidade é a mesma coisa que aprender a ociosidade; e, por outra parte, enquanto as crianças são bastante sérias, os trabalhos realmente livres têm bastante pouco de lúdicos.

Os princípios básicos da política educativa constituíam uma forma de reivindicar com os liberais republicanos, e ainda sabendo de suas limitações, a imperiosa necessidade de uma escola laica e obrigatória. Também lançou as bases para a reivindicação de um currículo integrador do ensino intelectual, da educação física e da formação científico-técnica pré-profissional, completando, assim, os princípios que, segundo Marx, deveriam distinguir a política educativa correcta da classe trabalhadora da política das classes dominantes e de outras direcções erróneas da política educativa da classe trabalhadora (a anarquista e a reformista de tipo lassaliano, fundamentalmente).

\section{A sociologia da educação de Durkheim}

A sociologia da educação de Durkheim assenta as suas raízes nas condições culturais e sociais da III República francesa, em geral, e na 
tradição positivista de Comte e no conflito político-ideológico entre o Estado laico e a igreja integrista católica, em particular.

Durkheim ocupa-se, pela primeira vez e de forma sistemática, da história da construção teórica dos fundamentos básicos da sociologia da educação e da sociologia do sistema de ensino, mediante o delineamento de seis linhas mestras:

1. Natureza e funções sociais da educação;

2. Bases gerais da sociologia da educação;

3. Sociologia da escola como meio moralmente organizado e como microcosmo social;

4. Sociologia histórica do sistema de ensino;

5. Sociologia da reforma do sistema educativo;

6. Sociologia do currículo.

O pensamento de Durkheim contém, sem dúvida, elementos teóricos e materiais críticos fundamentais para a construção da ciência social, em geral, e da sociologia da educação, em particular. Neste aspecto, é-lhe reconhecida a elaboração de um pensamento sistematizado no campo da educação.

\section{Natureza e funções da educação}

Antes de qualquer consideração relevante sobre o pensamento socioeducativo de Durkheim, vamos apoiar-nos neste autor para a primeira aproximação ao conceito de educação. A educação está intrinsecamente ligada à prática cultural, e é, por isso, considerada uma coisa humana. Fundamenta-se na acção reflectida sobre um ser humano, em desenvolvimento biológico e/ou social, por outro ser humano adulto, visando incutir no educando os elementos culturais identitários, como, por exemplo, saberes, maneiras de pensar, sentir e agir, tanto técnicas como morais, que as normas sociais consideram como aceites e desejáveis. Segundo Durkheim,

«A educação não é [...] mais do que o meio através do qual [a sociedade] prepara no espírito das crianças as condições essenciais de sua própria existência [...]. A educação é a acção exercida pelas gerações adultas sobre aquelas que ainda não alcançaram o grau de maturidade necessário para a vida social. Tem por objectivo suscitar 
e desenvolver na criança um certo número de estados físicos, intelectuais e morais que exigem dela tanto a sociedade política no seu conjunto como o meio ambiente específico a que está especialmente destinada» (DURKHEIM 1975: 52-53).

A educação, além de libertar o homem da sua essência natural, é sinónima de humanização. O homem não nasce feito, faz-se. Faz-se a si mesmo, mas só na medida em que é produto da sociedade, dos demais. Quer dizer, enquanto domina os seus instintos animais e interioriza a cultura, e com ela adquire novas qualidades físicas, mas sobretudo um determinado pensamento e um ethos, um sistema de hábitos mentais e práticos, uma concepção da realidade, uma forma de vida, uma moral concreta e uma formação pré-profissional. A educação não é criação espontânea do indivíduo, mas produção do mesmo. Porém, produção cultural e não meramente natural. Produção histórico-social do homem: porque a educação varia com cada cultura histórica e segundo o grupo social de que se trate (MIR 1990).

Assim, sem a sociedade, sem os demais homens, os vivos e os mortos, sem a tradição cultural e o presente histórico-social, o indivíduo humano não pode realizar-se como homem. Por isso, a educação inculca a realidade e o sentimento do poder e da autoridade do meio social ou da cultura do meio comum. Nessa mesma medida, a educação não é simples comunicação inter-individual, mas imposição, coerção e dominação. Supõe uma disciplina física, intelectual e moral, sua interiorização e a do sentimento, e a ideia da autoridade e do dever. As relações educativas são sempre relações de autoridade e de poder, e, nessa medida, de dominação. Mas de dominação do indivíduo animal pelo meio sociocultural; quer dizer, por si mesmas essas relações educativas não têm porquê implicar a dominação, o conflito ou a exploração de uns homens por outros.

$\mathrm{Na}$ verdade, acontece que, à medida que se complexifica a realidade social, essas relações se tornam conflituosas e a socialização se realiza sob o domínio económico, político e ideológico de determinados grupos e classes sociais, com a resistência relativa dos demais. Durkheim não fala claramente destas questões quando se debruça sobre a educação e o sistema escolar em geral; no entanto, elas constituem a matriz explicativa mais profunda do tipo de análise que encontramos em seus cursos sobre A evolução pedagógica em França. Para o autor, 
«A educação consiste numa socialização metódica da jovem geração. Pode dizer-se que em cada um de nós existem dois seres, mesmo quando inseparáveis a não ser por abstracção, que não deixam de ser distintos. O primeiro está constituído por todos os estados mentais que não se referem mais do que a nós mesmos e aos acontecimentos da nossa vida privada: é o que se poderia muito bem denominar o ser individual. O segundo é um sistema de ideias, de sentimentos e de costumes que exprimem em nós, não a nossa personalidade, mas o grupo ou os grupos diferentes em que estamos integrados; tais são as crenças religiosas, as opiniões e práticas morais, as tradições nacionais ou profissionais, as opiniões colectivas de todo o tipo. O seu conjunto constitui o ser social. Formar esse ser em cada um de nós, tal é ofim da educação» (DuRKHEIM 1975: 53-54).

Efectivamente, esta socialização do indivíduo se produz sempre em condições culturais, históricas e sociais determinadas, numa sociedade e em grupos sociais concretos. O processo educativo consiste na produção de um complexo de hábitos mentais, mediante uma socialização metódica diferencial, porque cada indivíduo vive numa determinada sociedade histórica e forma parte de uns grupos sociais ou de outros, tais como, de género, de status, de raça, de etnia ou de classe, fundamentalmente. Embora Durkheim não insista explicitamente nisto, há que distinguir, portanto, entre aqueles mecanismos sociais que se orientam à reprodução universal e «desinteressada» da educação e da cultura, e, obviamente, os outros, aqueles que servem para inculcar uma ideologia determinada, ou para reproduzir a desigualdade social e cultural, e que se encontram sob o controle dos grupos sociais dominantes.

Entendido em um sentido social mais amplo, o sistema educativo de uma sociedade modela constantemente a mente dos indivíduos que a constituem. E sua função principal consiste na inculcação de uma determinada visão da realidade - entendida como a do ambiente natural e a do meio social - , e do lugar que cada indivíduo ocupa nela, assim como de todo um conjunto de atitudes e de hábitos morais coerentes com a dita visão. Tudo isto, mais ou menos criado e enriquecido criticamente por cada indivíduo, acaba constituindo o núcleo objectivo de sua personalidade. Ora, quando a estrutura social é claramente desigual, os mecanismos sociais educativos inculcam também algum tipo de ideologia, reproduzem a divisão social da cultura e do trabalho, e, consequentemente, contrapõem a visão 
dominante da cultura como a única realmente legítima à dos grupos sociais subordinados, como inferior e relativamente ilegítima. Apesar de Durkheim não discorrer com abundância sobre esta segunda perspectiva da educação, quando analisa a sua problemática de forma genérica e sistemática, tem ideias muito claras a respeito dela: a leitura de sua história social do sistema de ensino e da pedagogia ocidental, sobretudo o caso francês, constitui precisamente a melhor prova disso.

\section{Possibilidades objectivas de uma ciência social da edu- cação}

Em primeiro lugar, debruçando-se sobre a possibilidade objectiva de uma ciência social da educação, Durkheim afirma a sua necessidade, precisa o seu objecto central - a saber: a génese, o funcionamento e a evolução do sistema de ensino e das doutrinas pedagógicas -, e fixa a sua terminologia básica.

A educação é um facto. Conhecer, compreender o que existe, é a função própria da ciência. Conhecer a educação será, portanto, a tarefa da ciência da educação. E, dado que a educação é um facto, pode haver dúvidas sobre a possibilidade dessa tarefa. Se a sociologia é saber da sociedade e das instituições sociais em geral, a sociologia da educação será o saber da educação e das instituições educativas, de sua articulação conjunta. Durkheim não usa a expressão «sociologia da educação»: a questão do nome parece-lhe algo secundária. Mas, em contrapartida, não tem a menor dúvida sobre a possibilidade objectiva deste novo saber: as leis da psicologia são irredutíveis às da psicologia do indivíduo, e o carácter externo e a homogeneidade real e lógica dos factos educativos como factos sociais permitem a aplicação rigorosa das regras do método sociológico. Por adição, a sociologia da educação não é só algo que se pode construir, mas é cada dia mais necessária, não só para os educadores, mas também para todos, para a sociedade em geral, enquanto instrumento eficaz para fazer frente à crise da sociedade contemporânea.

O sistema educativo é o conjunto articulado de práticas educativas de uma sociedade. Estudar a génese e o funcionamento do sistema educativo, assim como as doutrinas pedagógicas correspondentes a essa génese e a esse funcionamento, é o objecto principal da sociologia da educação. Tudo isso, em estreita relação com o sistema social 
- do qual o sistema educativo é parte, isto é, um subsistema -, e com uma atenção muito especial à anomia social e às suas principais manifestações. Durkheim conclui:

«Eis aqui, pois, dois grupos de problemas cujo carácter puramente científico é incontestável. Uns são relativos à génese; outros, ao funcionamento dos sistemas de educação. Em todas essas investigações se trata simplesmente de descobrir coisas presentes ou passadas, ou de verificar as suas causas, ou de determinar os seus efeitos. Constituem uma ciência; eis aqui o que é, ou, melhor dito, eis aqui o que seria a ciência da educação» (DuRKHEIM 1975: 81).

Em segundo lugar, Durkheim critica a orientação psicologista da pedagogia tradicional (embora sublinhe a necessidade da fundamentação psicológica da didáctica), assim como a sua natureza ideológica e normativa, e, em compensação, insiste na necessidade da fundamentação sociológica da pedagogia moderna.

Naturalmente, para Durkheim, a pedagogia deve abandonar a orientação psicologista tradicional e substituí-la por outra fundamentada na sociologia. Mas, isso não quer dizer que a psicologia não tenha uma função pedagógica. Como ciência da consciência individual é essencial para a didáctica. A sociologia proporciona o conhecimento da sociedade, que constitui a chave mestra para o conhecimento da escola. Depois da descoberta da sociedade e das necessidades sociais pela sociologia, a psicologia identifica os procedimentos mais idóneos para transmitir esses conhecimentos às crianças. Para o autor,

«Portanto, é sempre ao estudo da sociedade que devemos referir--nos; é unicamente aí onde o pedagogo pode achar os princípios de sua especulação. A psicologia poderá indicar perfeitamente qualé o melhor procedimento que se deva adoptar para aplicar à criança esses princípios uma vez que tenham sido estabelecidos, mas, em compensação, o que não poderá é fazer-nos descobri-los» (DuRKHEIM 1975: 115).

O psicologismo é uma consequência dos equívocos da pedagogia tradicional: da ilusão de autonomia da consciência individual e da consciência em geral, e da interpretação psicologista das relações educativas como relações puramente inter-individuais. Daí também a urgência da substituição deste pedagogismo utópico por uma prática pedagógica baseada na ciência social da educação. 
A pedagogia não é pura teoria, nem pura prática; nem só ciência, nem exclusivamente arte. É uma mescla de teoria e prática, algo que se encontra a meio caminho entre a ciência e a arte. Mas, para ser efectiva nas condições críticas da sociedade actual, a dita mescla deveria fundamentar-se na ciência social da educação. Porém, esta encontra-se ainda praticamente em sua infância: "A pedagogia não é mais do que a reflexão aplicada tão metodicamente como se possa aos temas da educação» (DURKHEIM 1982: 29).

O discurso da pedagogia sempre foi um discurso normativo. Refere-se ao dever ser, não ao ser, à realidade da educação. As doutrinas pedagógicas são, na realidade, a expressão dos desejos dos humanos sobre a base de certos interesses sociais práticos, materiais. São racionalizações ideológicas impostas por determinadas condições sociais e históricas. Com frequência aparecem como uma variante da literatura utópica, que se produz como forma de expressão de determinadas crises sociais. Tanto as pedagogias dominantes como as revolucionárias são igualmente ideológicas e normativas, e opõem-se à objectividade e à imparcialidade ou neutralidade científicas na medida em que os interesses que as condicionam não coincidem com os das classes sociais mais progressistas de cada momento e com os do conjunto da sociedade em geral.

A organização económica e política da sociedade, quer dizer, a produção e a distribuição da riqueza e do poder entre os diversos grupos sociais, fundamenta-se no seu sistema educativo e nos seus ideais pedagógicos, assim como na mobilidade dos indivíduos. Um determinado ideal pedagógico revela a visão sobre os objectivos da educação de um grupo social concreto numa sociedade e num dado período de tempo. E, nem sequer as técnicas pedagógicas são neutras e objectivas, mas estão em função do tipo de homem que cada sociedade 106 pretende criar ou que cada grupo social pretende modelar. Isto é algo que Durkheim ilustra com relativa profusão, começando por um dos casos históricos mais paradigmáticos: o da educação total do monacato cristão na Antiguidade, tão imitado muito cedo na história social do cristianismo, incluindo o presente. Em geral, «Cada tipo de povo tem uma educação que lhe é própria e que pode servir para defini-lo ao mesmo tempo que sua organização moral, política e religiosa» (DurkHeIM 1975: 102). 


\section{Função da educação escolar}

Teoricamente, num contexto social ideal fechado e puramente conservador, o sistema de ensino pode funcionar como um mecanismo social eficaz em ordem à inculcação de uma ideologia e um ethos determinados, à reprodução da desigualdade estrutural e à legitimação de grupos dominantes sem nenhum tipo de contestação ou de resistência. Porém, a experiência social tem mostrado que o mais frequente é o conflito entre os grupos sociais dominantes e os subordinados, e a consequente mudança social. Este conflito se reproduz também no seio do sistema de ensino, dando origem a diversas formas de contestação e de resistência. Além disso, é necessário considerar a correlação objectiva entre a divisão do trabalho e a desigualdade social em geral e a estruturação diferencial do ensino escolar. A socialização escolar implica até certo ponto a homogeneização dos alunos, por meio da inculcação de uma cultura universal, mas também a sua diferenciação mediante a transmissão de uma cultura distinta (particular), em função da divisão social do trabalho e das distintas formas de desigualdade social, embora Durkheim se refira explicitamente apenas à desigualdade relacionada com a divisão social do trabalho. Segundo o autor,

«É a sociedade que, para poder subsistir, necessita que o trabalho se distribua entre seus membros e se distribua entre eles de tal forma e não de tal outra. Este é o motivo pelo qual a sociedade se preocupa em preparar, através da educação, os trabalhadores especializados de que está necessitada. Por conseguinte, é para ela e também por ela que a educação se foi diversificando [...]. No entanto, seja qual for a importância dessas educações especiais, não se poderia rebater o facto de que não constituem toda a educação. Inclusive pode dizer-se que por si mesmas não se bastam; em qualquer parte que elas se encontrem não divergem umas das outras mais do que a partir de um certo ponto próximo do qual se confundem. Todas elas assentam sobre uma base comum [...]. Inclusive, essa base comum é a que passa geralmente a ser a verdadeira educação [...]. Os sistemas educacionais [...] estão tão obviamente vinculados a sistemas sociais determinados, que resultam inseparáveis deles» (DurKHEIM 1975: 100-101).

A escola moderna, o sistema escolar como tal, funda suas raízes no modelo cristão medieval, que, por sua vez, teve sua génese no 
monacato do século vi e no sistema de educação total: material e espiritual, ideológica e moral, profissional e quotidiana. Por sua complexidade e seus conflitos estruturais, a actual sociedade da informação e do conhecimento precisa de um modelo de educação relativamente similar, mas essencialmente crítico e pluralista. Porque, apesar das diferenças históricas e objectivas inegáveis, as suas principais funções sociais são equivalentes: a universalização do comportamento individual e a diferenciação profissional; a homogeneização e a diferenciação sociais, em geral. No tocante a outras considerações, hoje como ontem, o mais importante continua sendo a integração dos diferentes indivíduos e grupos sociais, o domínio das ideias, os sentimentos e as linhas de comportamento moral solidários, em contraposição aos particularistas e exclusivos, potenciados pelo neoliberalismo.

\section{A sociologia da educação de K. Mannheim}

Karl Mannheim esboçou a partir de posições teóricas e políticas o esquema geral de uma sociologia da educação, de um novo sistema de ensino, de um curriculum e de uma didáctica muito actuais.

\section{Princípios de uma política educativa democrática e eficaz}

A sociologia da educação de Mannheim não se limita estritamente à sociologia do sistema de ensino, enquadra-se na estrutura definida pelos seus pressupostos epistemológicos básicos e por sua visão pessoal dos princípios fundamentais de uma política educativa democrática e eficaz. O desenho desses princípios resume-se em: 1) educação para a mudança, garantida por uma formação básica rigorosa e comum; 2) educação para todos, o que implica a recusa decisiva do biologismo sociopedagógico e da lógica de «a barreira e o nível», própria da classe académica, a potenciação da igualdade de oportunidades e a democratização - não ao nivelamento para baixo - de todo o sistema; e 3) educação permanente em estreita relação com a realidade e a mudança social.

Deste modo, a educação escolar, concretamente, já não pode se considerar "só como uma introdução a uma sociedade dinâmica, mas como um agente das mudanças sociais» (MANNHEIM 1974: 
297). Quer dizer, deve transmitir aos jovens uma síntese da experiência tradicional e, ao mesmo tempo, pô-los também em condições de construírem por si mesmos uma nova sociedade, proporcionando--lhes, para o efeito, uma concepção do ambiente natural e do meio humano o mais científica possível, que lhes permita entender o seu lugar na realidade e comprometerem-se responsavelmente na resolução dos problemas mais importantes do presente.

A nova educação pretende ser autenticamente democrática, para todos. Mas, para tal, é necessário recusar a selecção psicométrica e o biologismo ideológico em geral, tratando de proporcionar, em compensação, a toda a população as mesmas oportunidades educativas. $\mathrm{O}$ autor fala, pois, de «democratização, não a nivelação, da educação», isto é, "ampla participação do povo na vida cultural [...] e supressão do complexo de inferioridade que as sociedades plutocráticas e autoritárias cultivam tão cuidadosamente» (MANNHEIM 1974: 123-133).

Para Mannheim, é por conta do controle do sistema académico--profissional tradicional e da imposição da lógica de «a barreira e o nível» que o «capital cultural» condiciona a educação social tanto como o capital económico, na medida em que «os interesses criados pelas classes educadas na limitação da educação superior são, pelo menos, tão poderosos como os interesses criados pelo capital» (ibidem: 322).

Portanto, a educação democrática, para a mudança e para todos, deve ser também uma educação permanente e de qualidade. Posto que «se há de transformar a educação na sólida base da sociedade, deverá prever-se a continuidade de sua organização» (ibidem: 322).

\section{Necessidade de uma educação democrática, permanente e de massas}

Para Mannheim, a «educação social» implica a rotura clara com o sistema de ensino tradicional e a necessidade de sua reforma radical. Esta passa, forçosamente, pela rotura crítica com a escola elitista e formalista tradicional, e pela necessidade de garantir a qualidade do ensino como critério guia básico da nova política educativa e, também, como prova social de uma democratização efectiva.

Tal como Durkheim, Mannheim concebe também a escola moderna como um meio moralmente organizado e em relação coerente com 
todo um conjunto de instituições, produto e garantia social do «planeamento para a liberdade», com a contribuição do sistema educativo ao consenso político próprio da «democracia militante», que se deve completar com a selecção democrática dos cidadãos mais aptos para exercer as principais funções sociais directivas. Pois:

«Não é possível uma sociedade sem grupos dirigentes responsáveis, $e$ [...] o remédio social diante a uma oligarquia não consiste em substituí-la por outra nova, mas em facilitar o acesso às posições de decisão aos mais aptos dentre as camadas inferiores» (MANNHEIM 1961: 101).

Segundo Mannheim, o sistema escolar da sociedade vitoriana era essencialmente elitista, próprio de uma «democracia comercial» para minorias e de uma época de prosperidade económica e consenso social. Daí a sua concepção escolástica e apartada da vida do estudo e da aprendizagem: o império do exame e do culto à memória, a erudição e o formalismo pedagógico. Ao contrário, o que hoje se necessita é de um sistema de ensino realmente democrático, que garanta a educação permanente e progressiva de todos os cidadãos, em estreita relação com a complexidade característica da sociedade da informação, global e de massas do nosso tempo.

No entanto, a renovação parcial e relativamente autónoma do sistema de ensino não é suficiente; para consolidar-se, deve apoiar-se na reorganização democrática geral do conjunto da sociedade:

«No passado existia uma separação absoluta entre o lar e a escola. Hoje, em compensação, leva-se a cabo tentativas de juntar os pais e os professores e coordenar desta maneira as influências vindas da escola com as que actuam no lar» (MANNHEIM 1961: 79).

O sistema de ensino não se deve limitar a preparar cada nova geração para a sua integração na vida profissional e na sociedade em geral, mas também tem de nuclear as experiências sociais que têm como objectivo básico a educação permanente dos cidadãos. Porque, hoje, a velocidade com que as mudanças se sucedem, alimentadas pelas aspirações tecnológicas e sociais, a rapidez com que a informação se torna obsoleta, não só não permitem um aprender para a vida, como também deslocam os objectivos da educação, na medida em que a sociedade se torna pouco estável, assim como as suas demandas. Por 
isso, a educação de jovens e adultos não deve ser concebida nem funcionar na prática como sucedâneo da universidade tradicional, mas como um mecanismo social eficaz para a actualização profissional, científica, democrática e cultural de todos os cidadãos, prestando uma atenção muito especial à difusão sistémica das visões científicas de conjunto sobre a natureza e a sociedade. Para Mannheim,

«A educação de adultos não continuará sendo uma espécie de substituto da educação universitária para os trabalhadores e empregados. Deverá dedicar-se a ajudar todos os cidadãos a adaptarem-se inteligentemente às exigências de mudança de uma sociedade nova [...] se a educação de adultos trata verdadeiramente de ajudar a criar cidadãos reflexivos, que se preocupam pelos problemas públicos em todas as actividades da vida, bem equipados para julgar os problemas correntes da democracia, terá de deixar de seguir os abalos superficiais do momento» (MANNHEIM 1974: 305-306).

Relativamente à reforma, Mannheim tinha consciência de que o êxito de qualquer processo de reforma educativa real (e não meramente retórica) que intentasse implementar se sujeitaria à vontade do professorado em participar dela. Para ele, o novo sistema de ensino da «democracia militante» precisa de um professor capaz de renunciar a todo o tipo de dogmatismo ideológico e disposto a tudo fazer para entender estritamente a cultura actual, adoptar uma visão mais ou menos unitária e de conjunto da mesma, e passar um conhecimento especializado e uma formação integradora aos seus alunos. Mas, para isso, necessita conhecer com profundidade tanto o meio social de procedência dos alunos como a estrutura geral da sociedade em que têm de se integrar como profissionais e como cidadãos. Para tal, Mannheim propõe a inclusão, no plano curricular de formação inicial dos professores, de matérias de tronco comum, como a psicologia, a sociologia geral, a sociologia da cultura e a sociologia da educação.

«Ou, para dizer em linguagem académica, o prévio: para ajudar a formação de uma educação à altura de nossos dias são necessários os seguintes cursos: 1) Sociologia da educação; 2) Ciência da conduta; 3) Sociologia da cultura; 4) Análise da estrutura social» (MANNHEIM 1961: 86).

Defensor da síntese da espontaneidade criativa e da disciplina inteligente como chave principal da nova pedagogia da «democracia 
militante», do «planeamento da liberdade» e do seu novo sistema de ensino, Mannheim critica ostensivamente a pedagogia autoritária, com o seu ideal da obediência cega, e as pedagogias liberal e libertária, por sua teoria da existência de uma natureza humana eterna e histórica e sua concepção da prática educativa em função da suposta espontaneidade total de cada indivíduo humano.

«Se a velha educação autoritária era cega às necessidades vitais e psicológicas da criança, o liberalismo do laissez faire perturbou o equilíbrio saudável entre o indivíduo e a sociedade...» (MANNHEIM 1961: 49).

"A teoria da educação liberal insistia em que os valores básicos e os objectivos da educação tinham carácter eterno e que o propósito final e exclusivo da educação consistia em fomentar o livre desenvolvimento da personalidade mediante a manifestação sem impedimento de suas qualidades inatas» (MANNHEIM 1961: 81).

À semelhança de outros autores do seu tempo, como Gramsci, Mannheim é de opinião que o naturalismo rousseauniano deve situar-se no seu contexto socio-histórico determinado, como produto lógico da reacção espontânea face ao domínio secular da pedagogia autoritária, embora tenha sido, na origem, uma atitude pedagógica progressiva. Em contrapartida, o caso dos movimentos de renovação pedagógica de inspiração rousseauniana (liberais ou libertários) é bem diferente. Além disso, denuncia os perigos da inculcação sistemática, da repressão autoritária e da obediência cega, que este tipo de tendências pedagógicas tenta passar a todo o custo através do seu cântico melódico dos valores da espontaneidade, da capacidade criativa e da experiência livre.

A existência histórico-social destas tendências pedagógicas ultra112 críticas é possível, precisamente, porque se trata de orientações teóricas que têm influências directas na educação social. Se ainda persistem é porque as minorias intelectuais que as alimentam se encontram relativamente protegidas das exigências mais comuns da existência social, enquanto se servem dessas posições ideológicas para cimentar seu individualismo imoderado, produzir sua identidade social e reproduzir sua situação relativamente privilegiada.

A prática educativa sempre modela o tipo humano mais incoerente com a estrutura social. Não se trata de nenhuma obrigação de ter 
de optar entre a pedagogia extrema da obediência cega e a liberdade utópica. Trata-se, sim, de organizar a educação de modo que se logre a melhor combinação possível entre a espontaneidade criativa e a disciplina inteligente: a personalidade democrática. Quer dizer, há que educar, acima de tudo, para a solidariedade afectiva e a coesão social; e, enquanto isso, há que fomentar a liberdade de julgamento, o equilíbrio psíquico pessoal e, em geral, as qualidades que distinguem a personalidade independente. Naturalmente, o primeiro princípio deverá caracterizar os primeiros níveis básicos da educação, e o segundo, progressivamente, os níveis médio e superior.

A democratização do ensino representa a possibilidade de uma autêntica revolução cultural, mas pode desaproveitar-se se não for cuidadosamente planeada. Não basta o desenvolvimento extensivo do sistema educativo moderno. O critério guia da sua democratização constitui a qualidade do ensino. E esta consiste em elevar sistematicamente o pensamento inferior ao nível superior, e não em nivelação para baixo. A reforma progressista do sistema de ensino deve garantir a qualidade, fomentar a progressividade e impedir a degradação do ensino. Porém, uma reforma demasiado rápida do sistema de ensino tradicional pode converter-se em uma fraude social (uma transformação social formal, aparente), que pode comprometer a cultura de uma sociedade determinada em geral.

\section{Curriculum oculto e curriculum manifesto}

Apesar de hoje se falar pouco da necessidade de distinção entre aquilo que se ensina (os conteúdos sobre os quais repousa a instrução escolar) e a forma como se ensina (o modo como se passa os conhecimentos inerentes aos conteúdos), é algo bastante importante e, naturalmente, complexo. Na opinião de Mannheim,

«Tudo o que ensinámos e, mais ainda, a forma como ensinámos, tem um efeito determinado na formação do carácter. [...] Sabemos hoje que o tipo de jogo que se proporciona e os detalhes íntimos da organização da escola são muito mais importantes do que os títulos que outorgamos a esses sistemas escolares. A organização social da escola, o tipo de "papéis" sociais em que se possa participar, o predomínio da competência ou da cooperação, e a existência de uma oportunidade maior para o trabalho em equipa do que para a tarefa solitária, todos 
são coisas que contribuem para o tipo de homem que há de formar-se em semelhantes situações» (MANNHEIM 1961: 81).

Por um lado, o curriculum deve considerar os efeitos educativos do modelo de escola: hierárquico ou democrático; para a competição individualista ou para a cooperação. Deve também impedir que a escola funcione como um mecanismo de reprodução das desigualdades sociais, tirando partido do sistema de internato e das melhores lições da experiência histórica em geral, e das vantagens educativas do grupo de iguais. Por outro, é importante a forma de estruturação do que hoje chamamos curriculum manifesto. Uma estruturação excessivamente fragmentada e especializada priva o aluno da possibilidade de alcançar em algum momento uma visão suficientemente unitária e crítica do seu próprio meio. Porém, com uma estruturação coerente, unitária e integral, ocorre precisamente o contrário.

Além disso, a formação plena da pessoa não se pode acautelar em absoluto com recurso a uma determinada disciplina curricular, mas que depende do funcionamento geral do curriculum escolar - oculto ou manifesto - e do conjunto da sociedade - da sua influência sobre os diversos grupos de indivíduos.

Mannheim sublinha a eficácia pedagógica das «ideias directrizes» durkheimianas, quer dizer: dos conteúdos gerais essenciais e potencialmente mais unificadores. Fá-lo no contexto da denúncia da frequente confusão da tolerância e da objectividade com a neutralidade, por mais intensa que seja a obsessão política pelo consenso social. Segundo o autor,

«Nem a tolerância democrática, nem a objectividade científica exigem que deixemos de defender as posições tidas por verdadeiras, nem que se evite toda a discussão sobre os objectivos e valores finais da vida» (MANNHEIM 1961: 95).

\section{A sociologia da educação de T. Parsons}

A obra que resume melhor a contribuição específica de Parsons para a sociologia da educação é The school class as a social system, publicada em 1959. Nesta obra, a escola é percebida como um subsistema social essencial, como agência de socialização e de diferenciação social. Além disso, está focalizada na sociologia da sala de 
aula (quando estuda a escola primária) e do centro escolar (no caso da escola do ensino secundário). Sua perspectiva ideológica é apenas relativamente parecida com a de Durkheim, de cujo objectivismo prescinde para adoptar uma orientação psicossociológica weberiana de corte reducionista. Mas, reproduz a visão durkheimiana da escola como «microcosmos social» especializado na homogeneização moral e na diferenciação pré-profissional dos cidadãos:

«O sistema escolar é um microcosmo do mundo laboral adulto, e a experiência nele constitui um campo muito importante de actuação dos mecanismos de socialização da segunda fase [a primeira é a família], a especificação das orientações do papel» (Parsons 1976, apud MiR 1990: 351).

É na escola que a criança vai, gradualmente, construindo a sua própria identidade, e é capaz de fazê-lo porque «gasta várias horas diárias fora de casa submetida a uma disciplina e a um sistema de recompensas essencialmente independente do administrado pelos pais» (PARSONS 1985: 53).

Nesta perspectiva, a escola primária representa a transição entre a família e a escola secundária, e, nesta fase, o mais importante é a ênfase na aprendizagem da motivação da realização e sua avaliação diferencial, pública e objectiva. Pois, no ensino secundário aumenta a internalização neutral, sem emoção e puramente abstracta da cultura e dos modelos mais universais do ser humano.

A socialização na sala de aula - e mais tarde no espaço escolar exige a aquisição de habilidades específicas para desempenhar os papéis de adulto e a aptidão adequada para desempenhá-los de forma responsável; quer dizer, para comportar-se da maneira que os outros esperam que se desempenhe cada papel específico. Mas, além disso, o aluno deve também identificar-se com os valores sociais dominantes e orientar-se para o exercício futuro de uma função ou um papel social mais ou menos determinado. Portanto, a socialização escolar tem duas dimensões fundamentais: instrumental e pré-profissional. A primeira de matriz moral e a segunda de fundo ideológico.

A dimensão moral e ideológica está relacionada com a função homogeneizadora do sistema de ensino. A escola distribui diferenciadamente as recompensas em função do rendimento académico individual. Neste sentido, o sistema de ensino hierarquiza o «nível das aspirações», que constitui uma espécie de ponte institucional que 
tem uma linha de bifurcação fundamental no final da escola superior: o ingresso ou a exclusão do ensino superior. Existe, ainda, «outra linha de demarcação entre os que chegam a um nível educacional, fora do ensino superior, e aqueles para quem a adaptação às expectativas educacionais é difícil em qualquer nível» (PARSONS 1985: 60).

$\mathrm{O}$ funcionamento da escola como mecanismo diferenciador começa com a igualdade formal de todas as crianças antes da competição no desempenho das tarefas escolares, a avaliação periódica do cumprimento de cada aluno, que não é puramente neutra, apoiada em critérios intelectuais e morais, às vezes, mais importantes que os propriamente académicos. A identificação emocional (ou não) e mental com o professor e com a visão da cultura e da moral que ele representa é mais decisiva para o êxito escolar do que atingir ou não um nível de instrução.

Parsons, à semelhança de Mannheim, não ignora a existência de um curriculum oculto e suas implicações. Mostra-se atento à problemática da inconsistência de status das crianças procedentes de estratos sociais mais baixos e com alto rendimento escolar, ou à relação existente entre o tipo de pedagogia e de organização escolar formal dos diversos centros, por um lado, e a forma de socialização familiar e o status socioeconómico dos alunos, por outro. Refere, por exemplo, que os alunos dos centros mais «democráticos» e pedagogicamente mais inovadores normalmente provêm de camadas sociais relativamente acomodadas e com uma cultura académica acima da média.

Do ponto de vista formal, o núcleo da sociologia da educação parsoniana circunscreve-se na visão da escola como canal institucional para a igualdade de oportunidades e o sucesso social dos mais aptos, na medida em que a instituição escolar - com o apoio da família inculca a todos os cidadãos a concepção da cultura e a moral universalizadoras imprescindíveis para o funcionamento da sociedade, legitimando, concomitantemente, a divisão social do trabalho e as 116 desigualdades sociais em geral, a ponto de conseguir, muitas vezes, o consentimento íntimo dos fracassados escolares. Assim,

«A avaliação da consecução e o facto de que esta é dividida entre a família e a escola não apenas fornecem os valores necessários para a internalização pelo indivíduo, mas também desempenham um papel essencial de integração para o sistema. É necessário que as oportunidades sejam reais e que se possa contar com o professor para respeitá-las, sendo este "justo" para premiar alguém que se possa mostrar 
capaz. É essencial observar que a distribuição das faculdades, embora estejam ligadas ao status familiar, não corresponde claramente com esta condição» (PARSONs 1985: 58-59).

Algumas críticas dirigidas a Parsons têm a ver com o facto de ter negligenciado o subjectivismo sociológico de Durkheim e empobrecido significativamente a orientação psicossociológica weberiana da lógica objectiva da dominação social. Como consequência lógica, Parsons prescinde da estruturação dual da cultura, da educação, da moral e da psicologia humana, e, com a sua interpretação normativista idealista, esquece a análise rigorosa da base material da cultura e da educação. Parte de pressupostos muito discutíveis: a neutralidade moral do sistema escolar e o seu lugar central como mecanismo de reprodução da cultura e da desigualdade social em conformidade com uma lógica estritamente meritocrática. O primeiro foi amplamente questionado por todos os clássicos e os principais neoclássicos da sociologia da educação. E, quanto ao segundo, é certo que Durkheim ou Mannheim o admitem, mas como projecto político e ideológico a promover de forma eficiente, e nunca como realidade histórica.

\section{Conclusão}

Desde a perspectiva clássica e neoclássica da sociologia da educação, considera-se a educação como um processo de transmissão formal da cultura e, como tal, só é possível dentro de um horizonte e ambiente cultural apropriados com os seus elementos de preservação, disseminação e inovação. Nas sociedades mais desenvolvidas, este processo está estruturado de modo a satisfazer as necessidades sociais de educação moral, cultura, de ensino especializado ligado a exigências de economia, de trabalhadores habilitados, cientistas e pessoal profissionalizado, e de alargamento do conhecimento por investigação, e outras.

Em termos muito latos e com muitas variações entre países e regiões, a classe social e os seus correlativos ainda têm um efeito sistemático na educabilidade e na selecção educacional; por exemplo, ainda hoje, as oportunidades de obter educação superior são maiores e melhores para uma criança da classe média do que para uma criança da classe trabalhadora. Ainda hoje, na segunda década do século xxi, os determinantes sociais do sucesso escolar são imensos, não obstante 
a tendência crescente para uma igualdade formal de oportunidades nos modernos sistemas educacionais.

Por isso, perceber o fenómeno educativo através da visão clássica e neoclássica permite-nos não apenas escrutinar a realidade educacional, mas também compreender melhor as interfaces do sistema e do processo de ensino. Com efeito, entre eles - clássicos e neoclássicos da sociologia da educação - , assiste-se a uma grande convergência de ideias, que se podem considerar complementares na prática educativa, na medida em que expressam de maneira geral a análise das instituições e organizações da educação. Porém, essa análise só cobra sentido quando conectada às relações funcionais entre a educação e outras grandes ordens institucionais da sociedade, tais como a economia, a religião, a política e a família.

Por isso, em plena sociedade da informação e comunicação, à escola desta sociedade não apenas cabe a função de definir objectivos, a distribuição de papéis, as disciplinas, o conteúdo e o método de aprendizagem, mas também lhe é exigido rever as suas relações com as outras modalidades de educação não formal (informal e profissional), para articular-se e integrar-se a elas e liderar o processo de socialização do conhecimento, com o propósito de formar cidadãos mais preparados e qualificados para corresponder às novas demandas sociais.

\section{Referências bibliográficas}

\section{CAmpenhoudt L. V.}

2012 (2. ${ }^{\text {a }}$ edição), Introdução à análise dos fenómenos sociais. Tradução de Eduardo de Freitas e revisão de Manuel Joaquim Vieira. Lisboa, Gradiva [«Trajectos»].

Durkheim E.

1975, Educación y sociología. Prefácio de Maurice Debesse; epílogo de Joan Volker e tradução de Janine Muls de Liarás. Barcelona, Península [«Homo sociologicus»].

1982, Historia de la educación y de las doctrinas pedagógicas: La evolución pedagógica en Francia. Apresentação de Félix Ortega; tradução de Maria Luisa Delgado e Félix Ortega. Madrid, Las Ediciones de la Piqueta [«Genealogía del poder»].

MANNHEIM K.

1961 [1944], Diagnóstico de nuestro tiempo. Tradução de José 
Medina Echavarría. México, Fondo de Cultura Económica [«Colección Popular»].

1974 [1963], Libertad, poder y planificación democrática. Tradução de Florentino M. Torner. México, Fondo de Cultura Económica.

MARX K.

1968, Crítica al programa de Gotha. Versión castellana revisada y ajustada a la edición soviética de 1953, editada pelo Instituto de Marxismo y Leninismo. Madrid, Ricardo Aguilera.

1975-1981, El capital. Crítica de la Economia Política. Tradución y notas de Pedro Scaron. volumes I, II e III. Madrid, Siglo XXI [«Biblioteca del pensamiento socialista»].

MARX K. \& ENGELS F.

1970, La ideología alemana. Crítica de la novíssima filosofia alemana en las personas de sus representantes Feuerbach, $B$. Bauer y Stirner y del socialismo alemán en las de sus diferentes profetas. Tradução de Wenceslao Roces. México, Ediciones Grijalbo S.A.

1978, Textos sobre educación y enseñanza. Madrid, Comunicación.

Mir R. F.

1990, Sociología de la educación: Guía didáctico y textos fundamentales. Madrid, Secretaria General del Consejo de Universidades.

Montoya B. L. C.

1986, «Limitaciones del análisis de Marx sobre la "legislación fabril” en El capital: discusión a propósito de su valoración sobre las "cláusulas educacionales"», Revista de Educación, n. ${ }^{\circ}$ 281, pp. 213-224.

Parsons T.

1976, El sistema social. Tradução de J. Jiménez Blanco e J. Cazorla Pérez. Madrid, Biblioteca de la Revista de Occidente. 1985 (3. ${ }^{\mathrm{a}}$ edição), «La clase como sistema social: Algunas de sus funciones en la sociedad americana» in Alain Grass (coord.), Sociología de la educación: Textos fundamentales. Madrid, Editorial, Narcea, pp. 2-7. 
Title: The perception of education from a sociological perspective

\begin{abstract}
This paper intends to discuss the knowledge of the main classical and neoclassical theorists of the sociology of education through the review of Marx's ideas and E. Durkheim, K. Mannheim and T. Parsons. It is clear, in this reflexive trilogy, a great convergence of ideas that can be considered complementary in educational practice, as expressed, in general, the analysis of institutions and education organizations, but this analysis only get sense when linked to relations functional between education and other institutional orders of society, such as economics, religion, politics and family. Therefore, for this reason, in the information and communication society the school is required to revisit its relations with other non-formal education approaches to articulate and integrate them and lead the process of socialization of knowledge aimed at training better prepared citizens and qualified to meet the new social demands.
\end{abstract}

Keywords: Sociology of education, K. Marx, E. Durkheim, E. Mannheim, T. Parsons.

\title{
António Inácio Rocha Santana
}

Sociólogo, exerce desde 2010, em comissão de serviço, a função de Director-Geral da Escola Superior Pedagógica do Kwanza Norte. É docente do Departamento de Sociologia (DS) da Faculdade de Ciências Sociais (FCS) da Universidade Agostinho Neto (UAN). Doutorado em Sociologia (2005) pelo Instituto de Sociología y Estudios Campesinos de la Universidad de Córdoba, Reino da Espanha e Doutorado em Ciências da Educação (2015) pela School of Social and Human Studies of the Atlantic International University, Estados Unidos da América (EUA). Tem participado com comunicação em alguns eventos nacionais e estrangeiros e dentre os quais se regista: «La comunicación docente: los comentarios de los estudiantes acerca de la actitud de los docentes en el aula», comunicação apresentada ao Congresso Pedagogía 2015, Palácio de Convenciones de La Habana, de 26 a 30 de Janeiro de 2015; "As manifestações do preconceito de cor em Angola», comunicação apresentada na 2. ${ }^{a}$ Conferência Internacional do CONCLADIN - Centro de Estudos das Culturas e Línguas Africanas e da Diáspora Negra, São Paulo, Universidade Estadual de São Paulo, Araraquara, Brasil, 18 a 21 de Maio de 2009; "África: imaginário, independência e desenvolvimento», Conversa temática apresentada aos estudantes de pósgraduação na 2. ${ }^{a}$ Conferência Internacional do Centro de estudos das Culturas e Línguas Africanas e da Diáspora Negra (CONCLADIN), São Paulo, Universidade Estadual de São Paulo, Araraquara - Brasil, 18 a 21 de Maio de 2009; "A imigração colonial portuguesa a Angola: um processo de construção de um projecto nacional para o porvir», comunicação apresentada no $x$ Congresso Luso-Afro-Brasileiro de Ciências Sociais, Braga, Universidade do Minho, de 4 - 7 de Fevereiro de 2009. Publicou, "As três formas históricas de desenvolvimento rural: uma breve incursão no contexto teórico do seu surgimento», Revista Letras e Ciências Sociais, n. ${ }^{\circ}$ 1, Janeiro-Junho de 2010, pp. 55-71.

[e-mail: antoniosantana200o@yahoo.es] 